\title{
Morphological and chemical analysis of tremolite related to natural asbestos in the road paving
}

\author{
${ }^{1}$ Department of Physics and Earth Sciences, University of Ferrara - via Saragat 1, 44121 Ferrara, Italy; *Corresponding author, E-mail: mrrlne@unife.it \\ ${ }^{2}$ ENEA, Italian National Agency for New Technologies, Energy and Sustainable Economic Development Fusion and Technology for Nuclear \\ Safety and Security Department Nuclear Safety, Security and Sustainability Division - via Martiri di Monte Sole 4, 40129 Bologna, Italy \\ ${ }^{3}$ SOCOTEC ITALIA, Ferrara Department - via Annibale Zucchini 69, 44122 Ferrara, Italy
}

(Received: February 1, 2020; Revised accepted: April 22, 2020)

https://doi.org/10.18814/epiiugs/2020/0200s05

Tremolite group minerals could be present in the aggregate used as filler in the mix asphalt floor in the road surfaces and are subject to wear for vehicular traffic and materials ageing. Dust produced by the degradation of asphalt surfaces can disperse tremolite group minerals present in road paving causing exposure by asbestos fiber to an increasing number of people and animals. In recent years, attention has been focused on naturally occurring asbestos (NOA) as the greatest frequency of lung cancer has been observed in environments characterized by rocks and soils rich in Tremolite that characterize asbestos minerals. Asphalt samples object of this study were collected in a motorway segment of the Lombardia Region (north of Italy) for an exposure assessment research on road paving workers. The evaluation was performed using a metrological approach based on petrographic and mineralogical analyses in order to reduce the epidemiologic risks and to define the best treatment strategies on waste management with sustainable costs in fulfilment of Council Directive 67/548/EEC (1967) and EC Regulation 1272/ 2008 (2008) (Paglietti et al., 2016). The fibers are generally not broken down to other compounds in the environment, but asbestos hazard could be related to the occurrence of tremolite fiber in road paving arises when natural weathering processes (e.g., erosion) or human activities (e.g., continuous passage of motorized vehicles) separate and break down the fibers, which could be lost into the environment as airborne and easily penetrate into the human respiratory tract (Punturo et al., 2019). Despite this, this work is not an epidemiological risk analysis but obtained data could be useful to other specialists to define the exposure risks.

\section{Introduction}

Asphalt is a natural mixture of solid and semifluid hydrocarbons, mostly consisting of bitumen; solid and dark in color, it is found as an impregnating agent for calcareous rocks (Greene, 1992).

Asphalt concrete (AC) is a composite material consisting of aggregate, asphalt binder (mastic), and air void. AC has been primarily used as a material in constructing road and airport pavements. (Xu, 2010; Romera et al., 2016) and in some cases it is mixed to fibers fillers of reinforcement (Xiong et al., 2015; Topini et al., 2018). The effectiveness of bituminous concrete is strictly influenced by the combination of base binder, additive type and dosage (Moreno-Navarro et al., 2017). However, under the effects of repeated vehicle loading at high temperature, moisture cycling, and low-temperature contraction, AC mixture is susceptible to distresses of rutting (permanent deformation), stripping (separation of asphalts from aggregates), and cracking, etc. Loss of performance of road paving is also due to climatic factors, i.e. temperature range (Bonica et al., 2016), moisture (Androjić et al., 2020), solar radiation, frequency and intensity of the rain and snow, frost, salt, etc.; and to anthropogenic impact as traffic and number of heavy vehicles traveling on the road, loads, speed, etc. (Qian et al., 2019; Assogba et al., 2020).

To guarantee safe circulation of road users, maintenance of road pavements with new asphalt overlays is required. Unfortunately, different studies to measure the potential environmental impacts of the asphalt mixtures life cycle rarely take into account the presence of asbestos for their reuse in the reconstruction of the road paving (Chen et al., 2009; Xu et al., 2010).

From the 1950s for about thirty years, some road paving in areas subject to severe deterioration (Du et al., 2019) and wear have been built with hot mix asphalt (HMA) (Landi et al., 2020) reinforced to asbestos in order to improve resistance and to reduce action of thermoclastism and cryoclastism (Slebi-Acevedo et al., 2019). It is therefore necessary to identify the presence of asbestos to avoid the risk of dispersion into the atmosphere of dangerous solid particles which can be inhaled by human and especially by road maintenance personnel in order to prevent exposure of the population to lung cancer caused by asbestos (Noonan and Pfau, 2010; Bourgault et al., 2014; Pfau and Noonan, 2019). The presence of asbestos in air and water has become a subject of health and environment concern (Mokhtari et al., 2019; Sąkol and Muszyńska-Graca, 2019; Taghizadeh et al., 2019). While the hazards of prolonged asbestos inhalation have been well established (Cox Jr, 2019; Nishimura et al., 2020), there does not yet appear to be 
clear answer concerning the toxicity of ingested asbestos (Fitzgerald and Rhodes, 2019; Zheng et al., 2019).

The number of workers exposed to asbestos since 1950 has greatly increased (U.S Department of Health and Human Services, 2001) caused to building construction and demolition and the deterioration and wearing of asbestos-containing materials. Worker exposure is a concern in the mining and milling of asbestos, during the manufacture of asbestos product (Heidrich et al., 2019; Kromhout et al., 2019).

This paper describes a method for the asphalt characterization. This study was requested by a private company from Ferrara city (North East of Italy) for the characterization of asphalts used in the road paving. The surfaces of each samples were analyzed using a portable Energy Dispersive X-Ray Fluorescence (ED-XRF). Fragment of each samples were prepared in order to perform X-ray diffractometric powder analysis (XRPD) and observation by scanning electron microscopy analysis (SEM-EDS). During XRPD and SEM-EDS analyzes, presence of asbestos fibers was unexpectedly observed in some samples.

\section{Materials and methods}

\section{Sampling}

Three samples were collected in the North of Italy in a motorway section in the Lombardia region, with a wet core drill of $5 \mathrm{~cm}$ cylin- drical section (Fig. 1). The samples were stored individually in a double envelope to prevent contamination.

Petrographic study on the surfaces of the samples was conducted using a portable X-ray fluorescence (ED-XRF). No thin sections were made to avoid risks of exposure to hypothetical fiber particles. The samples were analyzed by ED-XRF as it is without any preparation or manipulation.

Fragments of degradation asphalt paving were crushed in water, sieved and collected on filter. Two different particle size fraction were obtained by sieving: samples pulverized granulate with a diameter between $1 \mathrm{~mm}$ and $0.063 \mathrm{~mm}$; samples granulate crushed with a diameter less than $0.063 \mathrm{~mm}$. All these samples were filtered and dried in stove in glass containers in order to perform X-Ray Diffractometric Powder analysis (XRPD) and observation by scanning electron microscopy analysis (SEM-EDS). For SEM-EDS analysis the samples were not metallized.

\section{Chemical and Mineralogical Characterization}

Chemical elements in asphalt samples were determined by EDXRF, using a portable $\mu$-XRF spectrometer ARTAX ${ }^{\mathrm{TM}} 200$ (Bruker AXS Microanalysis GmbH, Germany) for the spectroscopic analysis. The instrument consisted of an X-ray tube with a Mo target and an SSD Peltier-cooled detector $\left(10 \mathrm{~mm}^{2}\right.$ active area and resolution of $<155 \mathrm{eV}$ at $10 \mathrm{kcps})$. The system performs a simultaneous multi-ele-

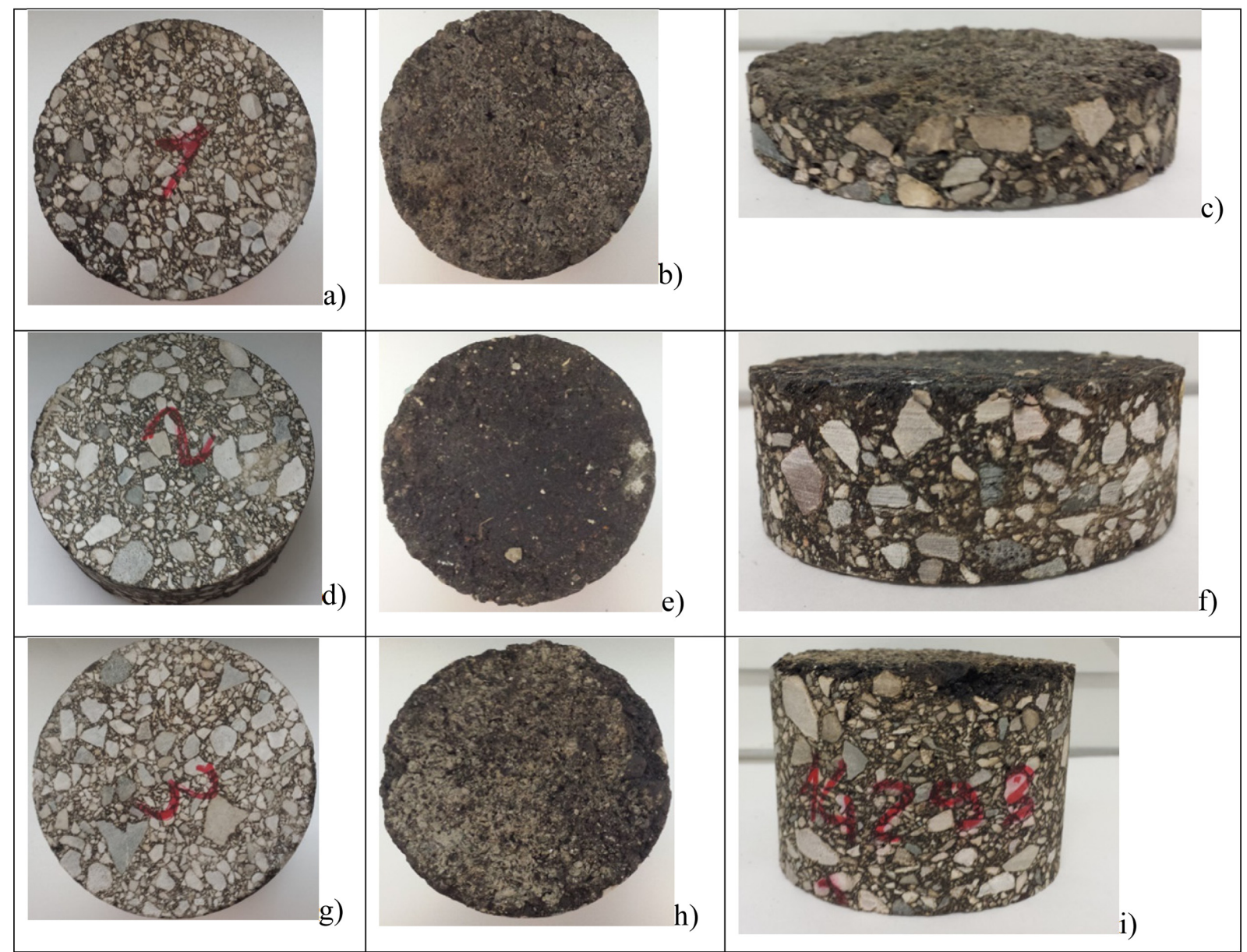

Figure 1. Photo images that allow to realize the macroscopic characterization of the three asphalt samples: a) b) c) sample 1; d) e) f) sample 2; g) h) i) sample 3; a) d) g) section of samples; b) e) h) surface of samples; c) f) i) lateral part of each samples. 
ment analysis in the element range from $\mathrm{Na}$ (11) to $\mathrm{U}$ (92). The maximum voltage and current of $50 \mathrm{kV}$ and $1500 \mu \mathrm{A}$, respectively, were used to excite the secondary fluorescence X-rays. A collimator with a diameter of $1 \mathrm{~mm}$ was used to collect the emitted secondary X-rays from a surface area of about $0.79 \mathrm{~mm}^{2}$ in air. The measurement is nondestructive. The major elements determined as oxides were $\mathrm{SiO}_{2}$, $\mathrm{TiO}_{2}, \mathrm{Al}_{2} \mathrm{O}_{3}, \mathrm{Fe}_{2} \mathrm{O}_{3}, \mathrm{MnO}, \mathrm{MgO}, \mathrm{CaO}, \mathrm{K}_{2} \mathrm{O}$ and the trace elements were $\mathrm{Zn}, \mathrm{Cr}, \mathrm{Cu}, \mathrm{Sr}$ and $\mathrm{S}$. The accuracy and precision of data were evaluated using certified international standards (JSd-1 and JSd-2 stream sediment powder, Geological Survey of Japan, Tsukuba, Japan). Accuracy was generally lower than $2 \%$ for major oxides and less than $5 \%$ for trace elements: the detection limits for major oxides were $0.03-0.05 \%$ and for trace elements 1-2 ppm. The qualitative data obtained were expressed as single element weight.

Moreover, mineralogical determinations of some aggregates, previously grinded using water and then dried, were carried out through Xray diffractometric powder analysis (XRPD) using a Philips PW1860/ 00 diffractometer, with a graphite filtered and a $\mathrm{Cu} \mathrm{K \alpha}$ radiation $(1.54 \AA)$ in a $2 \theta$ angular range $5-75^{\circ}$, with a $5 \mathrm{~s} / \operatorname{step}\left(0.02^{\circ} 2 \theta\right)$ (Marrocchino, et al., 2010).

The morphological and chemical characterization was carried by a Scanning Electron Microscope (SEM) Zeiss EVO MA15 (Carl Zeiss AG, Oberkochen, Germany) equipped with an Energy Dispersive Xray Spectrometer (EDS) INCA 300 (Oxford Instruments, Abingdon, UK) for X-ray microanalysis. The SEM-EDS high magnification images of the sample surfaces were performed using the SmartSEM software (Zeiss) (Telloli, et al., 2018). For SEM examinations, a piece of each sample was firmed on an SEM stub utilizing double-sided conductive adhesive tape.

\section{Results}

\section{Macroscopic Characterization}

All samples can be classified as bituminous conglomerates characterized by good quality aggregate of limestone breccia with good physical-mechanical resistance incorporated in a bituminous matrix (Fig. 1).

In all analyzed samples, the aggregate was constituted of limestone granules characterized by sharp-edged fragments with jagged contours and it was well graded, with a prevalent fraction with a diameter major than $4 \mathrm{~mm}$. These features led to hypothesize that the aggregates used was probably obtained by crushing and sieving limestone rocks, or they could come from gravel quarries.

The aggregates were predominantly composed by microcrystalline rocks with carbonate composition and were submerged in an asphalt matrix mixed with an asbestos filler (not exceed 5\%, observed using stereomicroscope). In the samples 1 and 2 grains orientation was almost absent, the aggregates were well graded and well mixed with matrix. Sample 3, instead, was less well graded than samples 1 and 2, with fractions with different dimensions. In all samples, the grains were well submerged in the matrix; this implies that granules do not had contact each other, being evenly coated with bitumen. They were characterized by a medium degree of thickening: low macro-porosity in samples 2 and 3 , while in sample 1 several macro vacuoles were pres- ent in the bituminous fraction. No ravelling phenomena or other forms of degradation were observed, testifying optimal aggregate bitumen bonds. The surface of the bituminous layer was rough in sample 1, while sample 2 had a surface without roughness and intermediate roughness characterized sample 3 . All samples seem to have a positive correlation between macro porosity and surface roughness. Sample 3 was characterized by a layer of dust due to accumulation phenomena, conversely in sample 2 was not evident any accumulation of dust, but a biological attack with abundant development of fungal hyphae.

\section{ED-XRF Data Analysis}

Clasts and bituminous fraction had been analyzed for each samples. Sample 1 was characterized by different particle size, as shown in figure $2 \mathrm{a}$. The nature of the clasts was mono-compositional consisting exclusively of calcium carbonate. Iron and strontium were also present (Fig. 2a). In other analyzed clasts, Zn, Ti, V, Mn and S were also reported. The bituminous fraction (Fig. 2b) was characterized not only by Ca element, that could be related to the presence of carbonate mineral fragments, but also high peaks of $\mathrm{Fe}$ and $\mathrm{Cr}$ and alum potassium silicates, represented by high peaks of Si and K. Finally, presence of small peaks of $\mathrm{Ni}, \mathrm{Ti}, \mathrm{Zn}$ and $\mathrm{Sr}$ elements were also detected, as shown in the graph of figure $2 \mathrm{~b}$. These elements could be related to vehicular traffic pollution that could be adsorbed by the fracture in the asphalt.

Figure 2c shown the ED-XRF spectrum of clasts in sample 2, that were characterized by calcium carbonate. Small peaks of $\mathrm{Fe}, \mathrm{Mg}, \mathrm{Si}$ and $\mathrm{K}$ elements were also present, as shown in the graph of figure $2 \mathrm{c}$. High peak of $\mathrm{Ca}$ reflected the low thicknesses of the bituminous layer therefore the presence of the carbonate aggregate emerged compositionally. Abundant in the bituminous fraction were $\mathrm{S}$ and $\mathrm{Fe} ; \mathrm{Ni}, \mathrm{Cr}$, $\mathrm{Cu}, \mathrm{Zn}$ and $\mathrm{Sr}$ elements were also detected (Fig. 2d) probably related to vehicular traffic pollution that could be adsorbed by the fracture in the asphalt as in the sample 1 .

Sample 3 was characterized by high concentration of calcium in the clasts analyzed, probably due to the presence of calcium carbonate in the majority fraction of the sample (Fig. 2e). The bituminous fraction appeared wrinkled and thin in correspondence with the clasts this could cause a partially transparent to X-rays from which an important peak of calcium related to the presence of carbonate clast. Compared to sample 1 and 2, sample 3 shown the bituminous fraction with a lower peak of transition metals, especially for iron and sulphur. Low concentrations of $\mathrm{Sr}$ and $\mathrm{K}$ were also detected (Fig. 2f).

\section{XRPD Data Analysis}

Samples pulverized granulate using water and then dried with a diameter between $1 \mathrm{~mm}$ and $0.063 \mathrm{~mm}$ and samples granulate crushed with a diameter less than $0.063 \mathrm{~mm}$ were analyzed by XRPD. The semi-quantitative data obtained were processed and the average of the results were inserted in a single graph shown in figure 3.

Figure 3 a shows the analyses of the fraction with diameter less than $0.063 \mathrm{~mm}$. Sample 1 and sample 3 had similar pattern characterized by a high mineral abundance of carbonate clasts represented by high peak of calcium and magnesium. The presence of magnesium was probably due to the presence of dolomite clasts. 


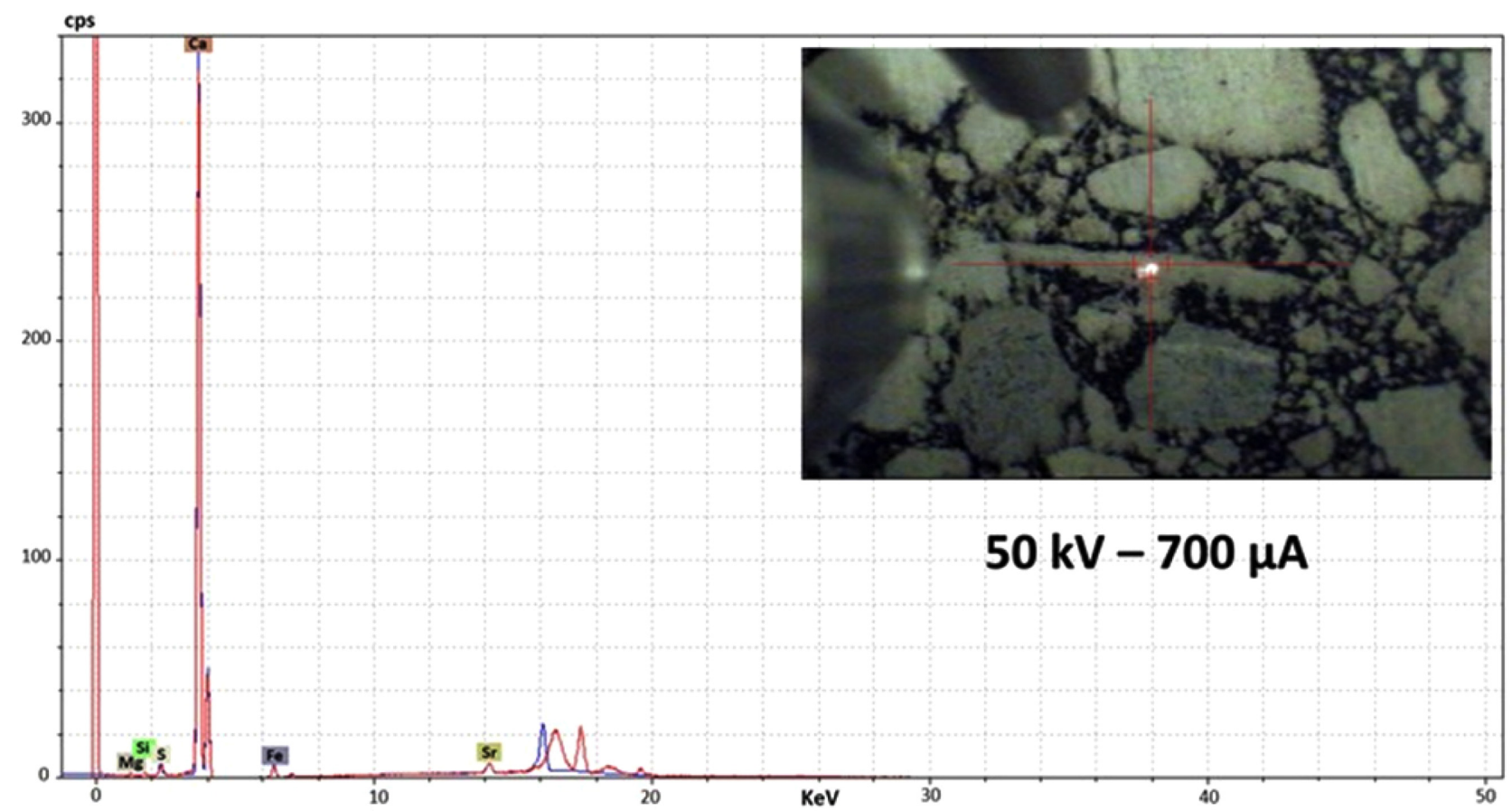

a)

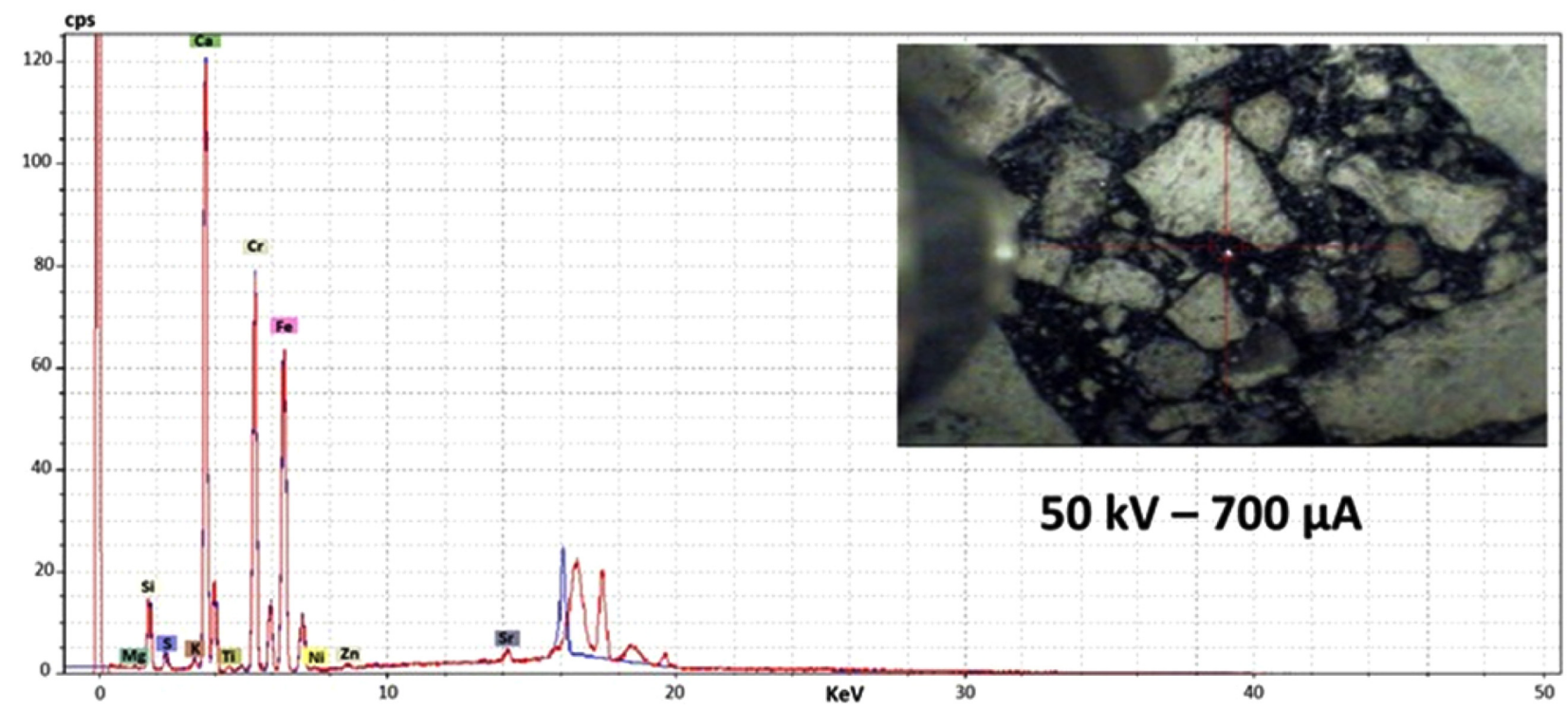

b)

Figure 2. ED-XRF spectrum and photo imaging of each samples analyzed at a high voltage of $50 \mathrm{kv}$ and $700 \mu$ A: a) clast in sample 1; b) bituminous fraction in sample 1; c) clast in sample 2; d) bituminous fraction in sample 2; e) clast in sample 3; f) bituminous fraction in sample 3.

In addition, small peaks of tremolite species and the absence of chrysotile. On the other side, sample 2 shown the same abundant of carbonate clasts represented by high peak of calcium and magnesium as in the other two samples, peaks of tremolite species but also a small abundant of chrysotile, that could be related with asbestos.

For this reason, sample 2 has been much more wet grinded and the fraction with diameter between 1 and $0.063 \mathrm{~mm}$ was analyzed. Figure $3 \mathrm{~b}$ shows the results: confirming the presence of chrysotile and tremolite species.

\section{SEM-EDS Data Analysis}

Morphological and microstructural characterization were performed using SEM analysis in order to detect the morphology of the particles, recognize the presence of fiber phases (Tremolite asbestos), identify the fibers dimension (diameter and length) and any degree of aggregation (presence of growths, micro fractures, etc.). The morphological analysis was conducted by microanalysis aimed to identify the chemical and mineralogical composition of the observed granules.

Two different particle size fraction were obtained by sieving and analyzed by SEM-EDS: samples pulverized granulate with a diameter between $1 \mathrm{~mm}$ and $0.063 \mathrm{~mm}$ and samples granulate crushed with a diameter less than $0.063 \mathrm{~mm}$.

\section{Size fraction $<0.063 \mathrm{~mm}$}

Table 1 shows the average of the data obtained by SEM-EDS analysis of the three samples collected and expressed in oxide weight (\%). 


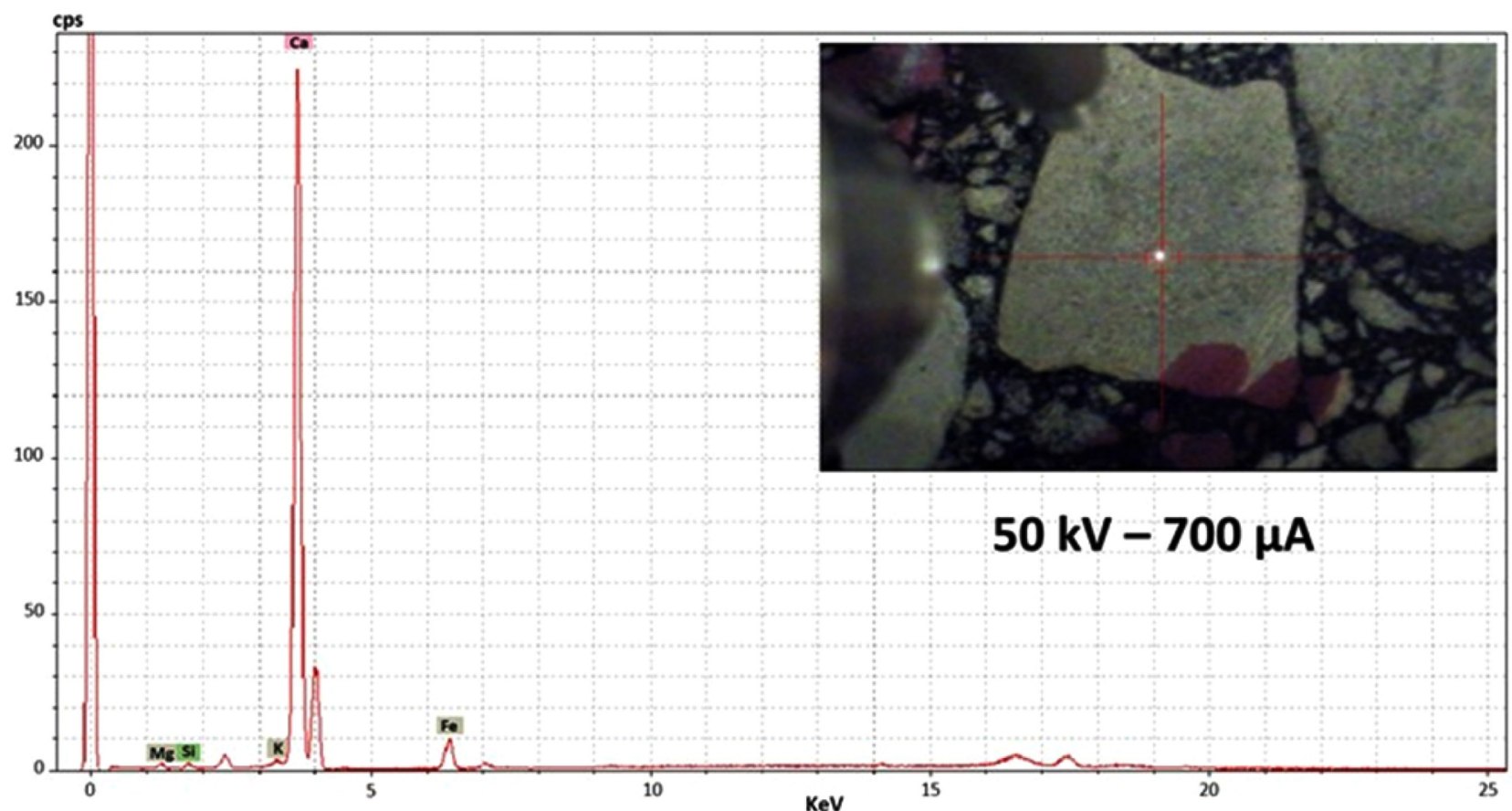

c)

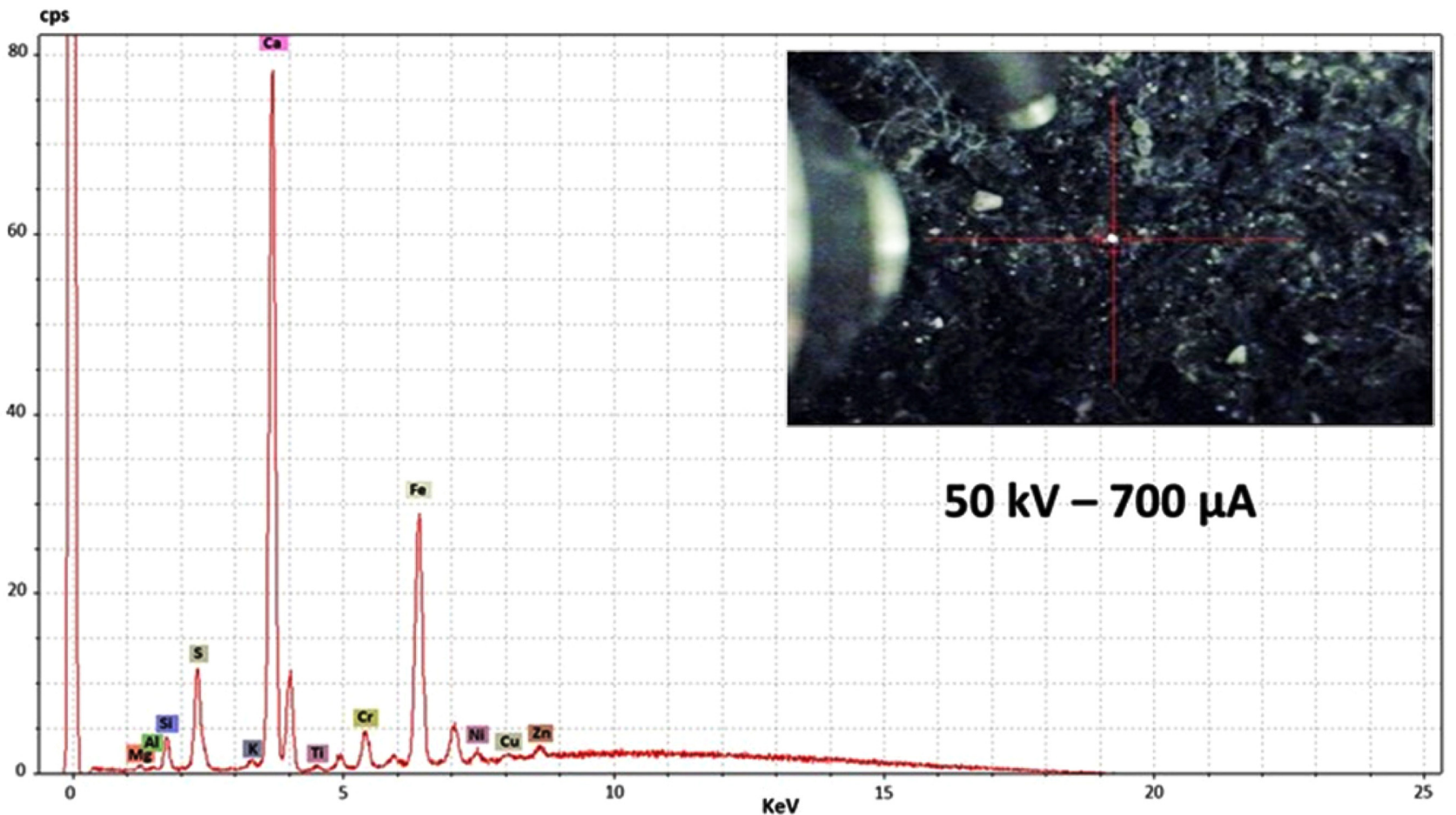

d)

Figure 2. Continued

For each samples, superficial layer called S and internal layer called I were analyzed.

Both in the internal and external layers of sample 1 the results show an absence of asbestos particles. The matrix was granular with rounded particles (as shown in Fig. 4a and 4b) and the chemical composition not highlight high $\mathrm{Mg}$ concentration that could be typical of the asbestosis phases. $\mathrm{Mg}$ was low abundant and compatible with the clay composition of the matrix or associated with the presence of dolomite clast. For this reason, it was not possible to define if $\mathrm{Mg}$ concentration was due to the presence of dolomite or to asbestos particles.
Figure $4 \mathrm{c}$ shows particles in sample $2 \mathrm{~S}$, that were higher than particles in sample $1 \mathrm{~S}$, so the sample $2 \mathrm{~S}$ was less powdery. Also in sample 2 the particles were generally rounded. High $\mathrm{Ca}$ and $\mathrm{Mg}$ concentrations could be related to the presence of calcite and dolomite; the percentage of silicates was low being the $\mathrm{SiO}_{2}$ very low. On the opposite, sample 2I results (Table 1) show the presence of asbestos particles: Si$\mathrm{Mg}$ ratio was consistent with the presence of chrysotile (Gronow, J., 1987; Kimizuka et al., 1987; Falini et al., 2002).

The particles in the sample $3 \mathrm{~S}$ were mainly massive (Fig. 4e). A few slightly fiber phases are observed, but due to the presence of 


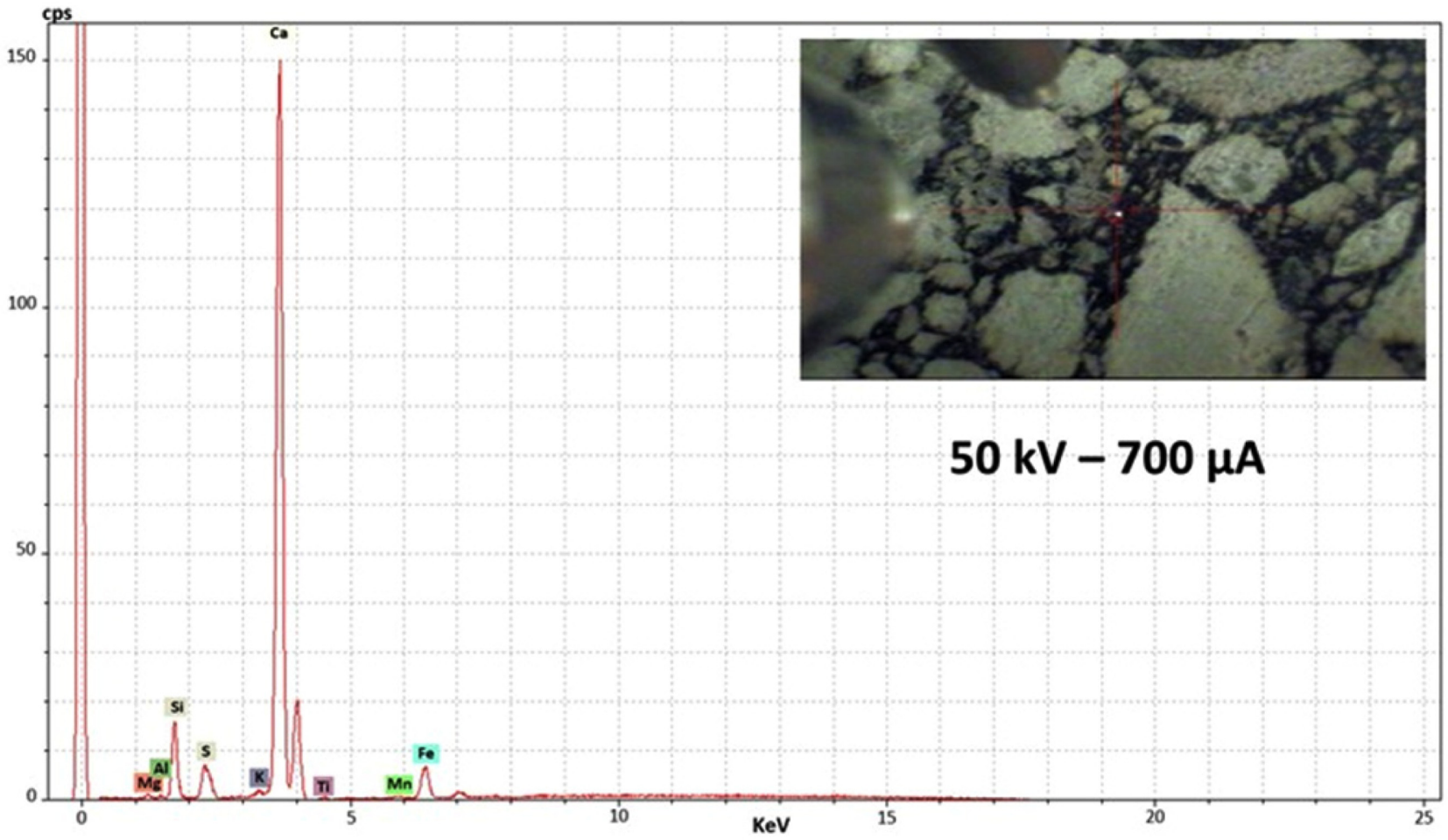

e)

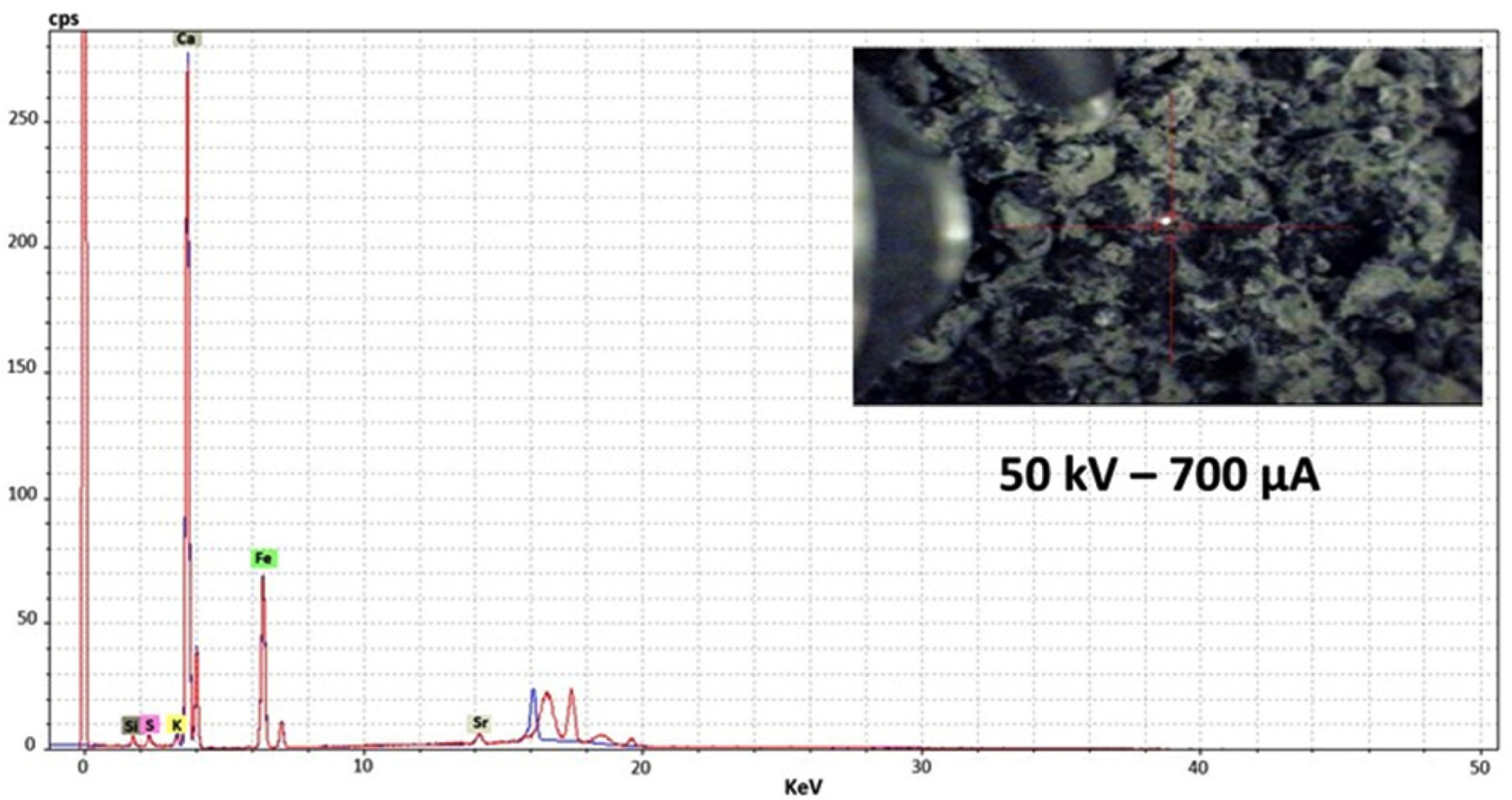

Figure 2. Continued

dolomite there is a high concentration of $\mathrm{Mg}$ which does not allow to identify its nature. Table 1 and figure $4 \mathrm{f}$ show the total absence of asbestos particles in sample 3I.

\section{Size fraction between $1 \mathrm{~mm}$ and $0.063 \mathrm{~mm}$}

Only in sample 2, SEM-EDS analyzes show the presence of asbestos particles in the form of chrysotile (Table 2 and Fig. 5).

Table 2 shows the high concentration of $\mathrm{Si}$ and the low concentration of Ca respect to Table 1, that could confirm the presence of the fiber.
SEM observations highlighted that tremolite asbestos and actinolite appear straight and show a slender needle-like crystal habit with a length longer than $10 \mu \mathrm{m}$. It is worth remembering that fibers are composed of many fibrils, which tend to split up along the fiber elongation axis (Belluso et al., 2017).

\section{Discussion and Conclusion}

Morphological and chemical characterization of asphalt samples 


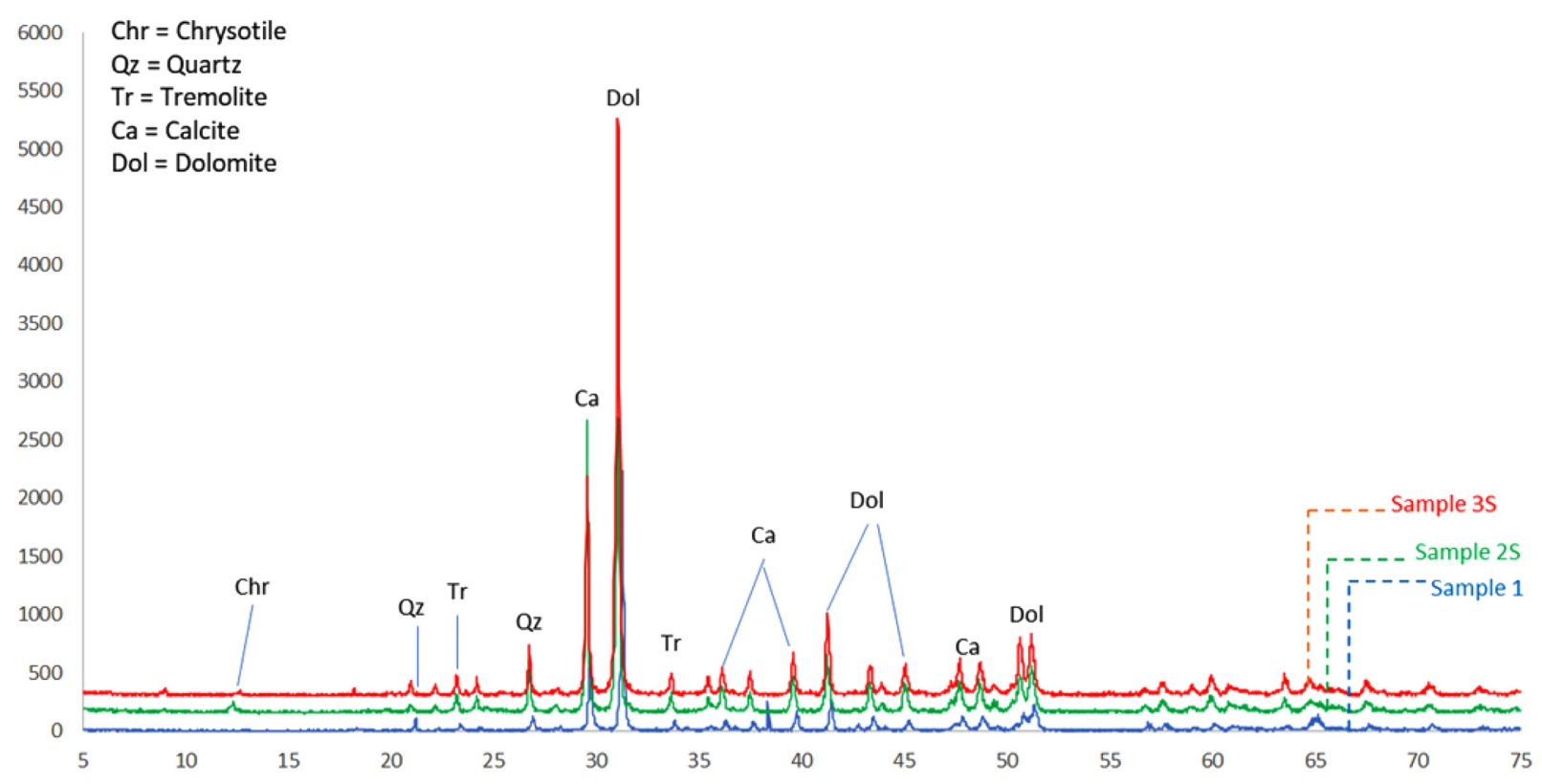

a)

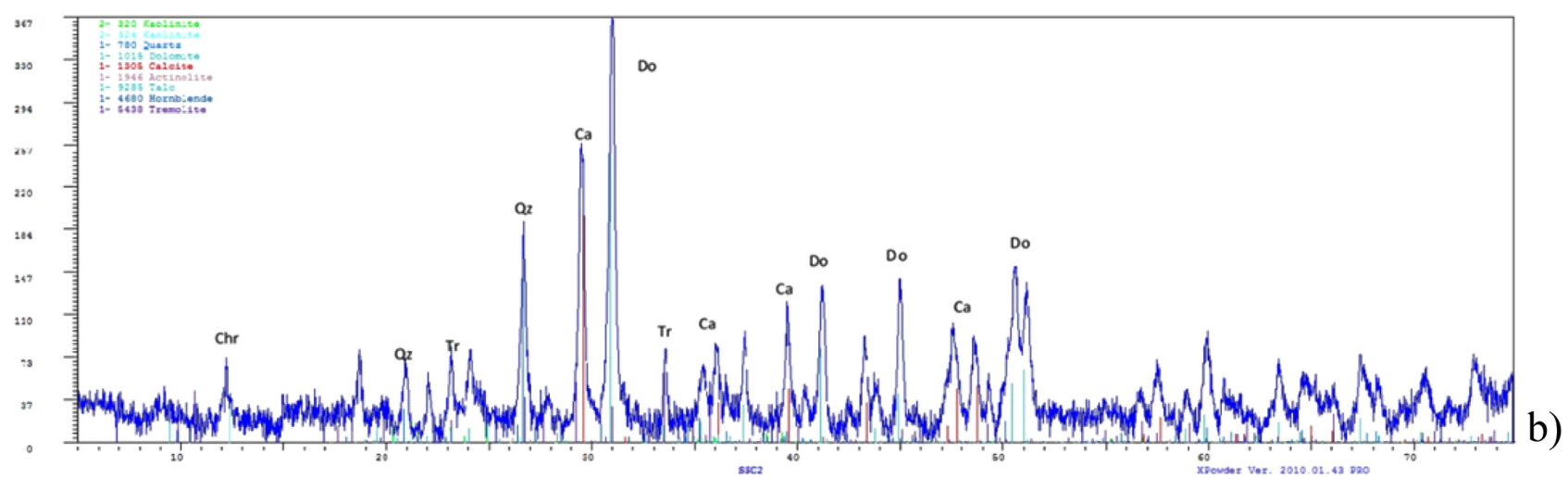

Figure 3. XRPD spectrum: a) spectrum of the fraction with diameter less than $0.063 \mathrm{~mm}$ of all the three samples analyzed (sample in blue, sample 2 in green and sample 3 in red); b) spectrum of the fraction with diameter between 1 and 0.063 mm of sample 2.

Table 1. SEM-EDS average data analysis of the three samples analyzed expressed in oxide weight (\%): "S" means superficial layer and "I" means internal layer

\begin{tabular}{|c|c|c|c|c|c|c|}
\hline Element & $1 \mathrm{~S}$ & $1 \mathrm{I}$ & $2 \mathrm{~S}$ & $2 \mathrm{I}$ & $3 \mathrm{~S}$ & $3 \mathrm{I}$ \\
\hline $\mathrm{C}$ & 11.58 & 7.38 & 13.61 & 17.41 & 12.51 & 8.37 \\
\hline $\mathrm{O}$ & 45.96 & 51.54 & 55.24 & 55.24 & 44.38 & 50.72 \\
\hline $\mathrm{Na}$ & 0.74 & 0.28 & 0.00 & 0.45 & 0.26 & 0.11 \\
\hline $\mathrm{Mg}$ & 2.27 & 6.11 & 7.64 & 5.45 & 2.24 & 6.13 \\
\hline $\mathrm{Al}$ & 6.26 & 2.43 & 0.45 & 1.22 & 7.18 & 3.58 \\
\hline $\mathrm{Si}$ & 12.27 & 13.40 & 4.32 & 2.53 & 13.98 & 14.13 \\
\hline S & 0.00 & 0.00 & 0.16 & 0.29 & 0.00 & 0.00 \\
\hline $\mathrm{Cl}$ & 0.00 & 0.00 & 0.00 & 0.32 & 0.00 & 0.00 \\
\hline K & 0.67 & 0.14 & 0.15 & 0.25 & 0.85 & 0.46 \\
\hline $\mathrm{Ca}$ & 18.60 & 14.95 & 13.81 & 15.93 & 17.02 & 13.72 \\
\hline $\mathrm{Ti}$ & 0.00 & 1.01 & 0.00 & 0.00 & 0.00 & 0.98 \\
\hline $\mathrm{Mn}$ & 0.00 & 0.00 & 0.40 & 0.00 & 0.00 & 0.00 \\
\hline $\mathrm{Fe}$ & 1.65 & 2.77 & 4.20 & 0.92 & 1.58 & 1.80 \\
\hline Totals & 100.00 & 100.00 & 100.00 & 100.00 & 100.00 & 100.00 \\
\hline
\end{tabular}

for road paving have shown the presence of asbestos fibers especially in the size fraction with diameter between $1 \mathrm{~mm}$ and $0.063 \mathrm{~mm}$. The results of the analysis in the fine fraction with diameter less than $0.063 \mathrm{~mm}$ show the total absence of asbestos, probably too small and 


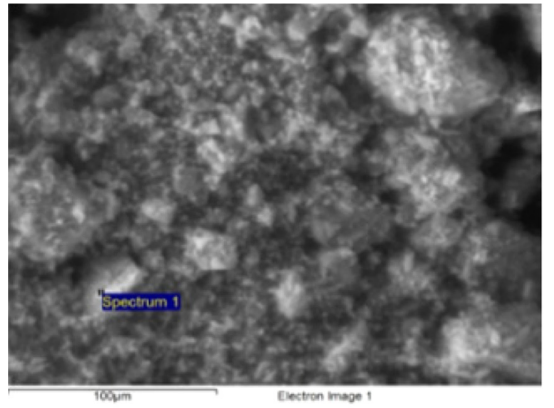

a)

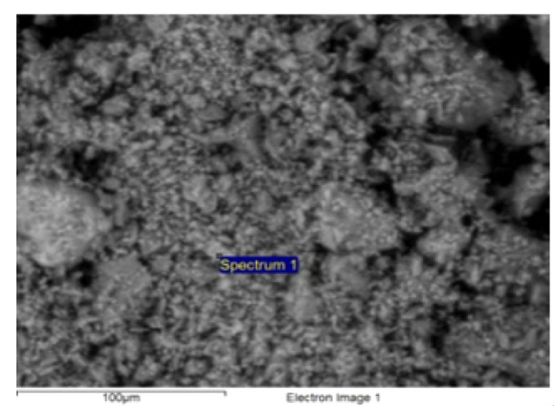

b)
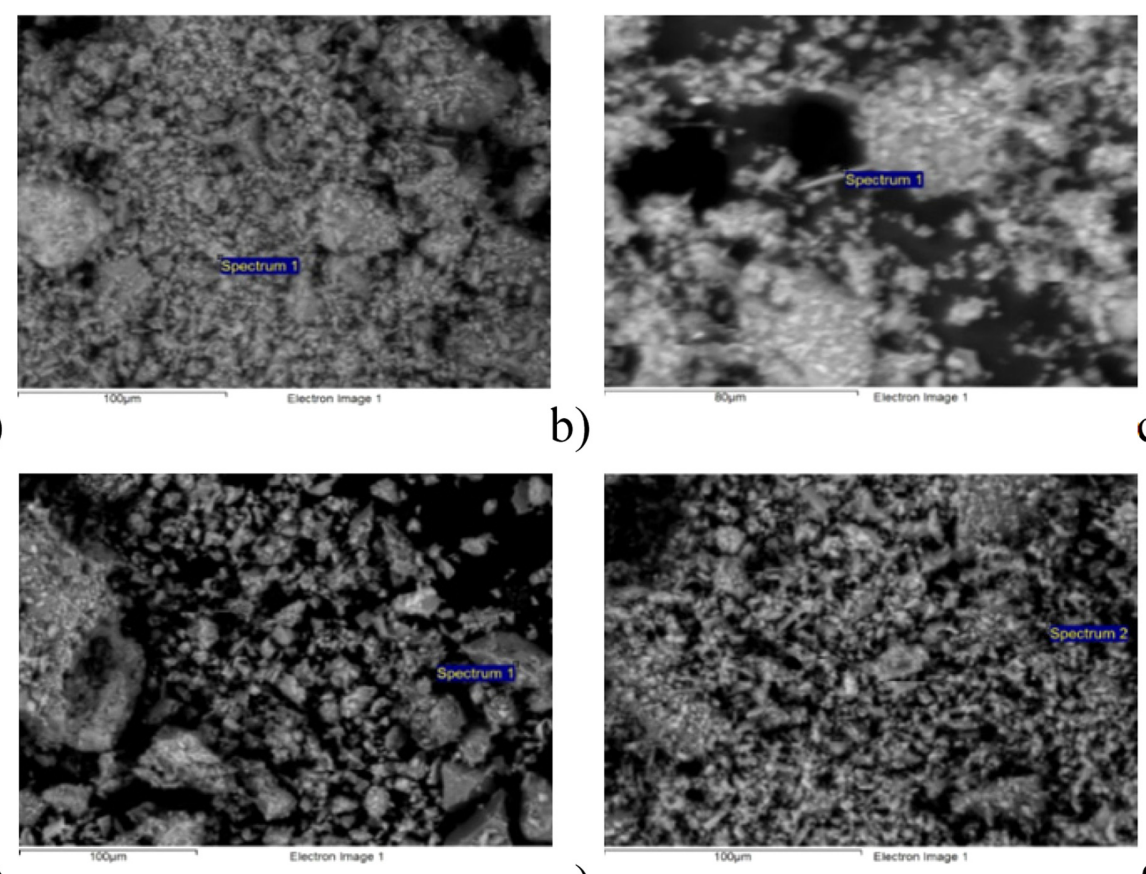

d)

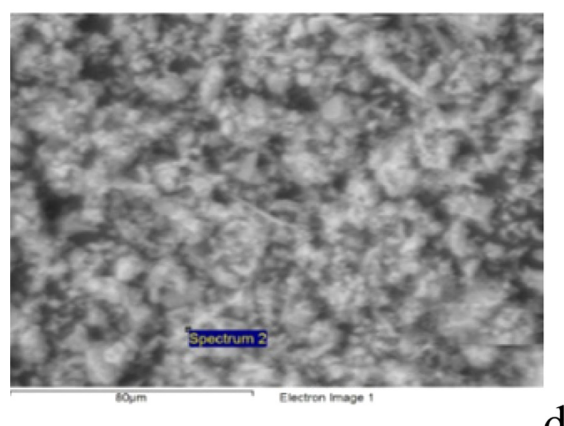

e)

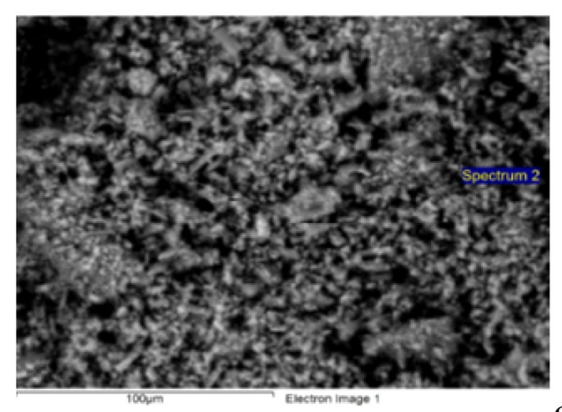

Figure 4. SEM imaging of the superficial (S) and internal (I) layer of each samples collected: a) sample 1S; b) sample 1I; c) sample 2S; d) sample $2 I$; e) sample $3 S$; f) sample $3 I$.

Table 2. SEM-EDS average data analysis of the three samples analyzed expressed in oxide weight (\%): "S" means superficial layer and "I" means internal layer

\begin{tabular}{ccc}
\hline \hline Element & $2 \mathrm{~S}$ & 2I \\
\hline $\mathrm{C}$ & 7.39 & 8.78 \\
$\mathrm{O}$ & 52.63 & 51.36 \\
$\mathrm{Mg}$ & 17.37 & 16.90 \\
$\mathrm{Al}$ & 5.24 & 4.08 \\
$\mathrm{Si}$ & 14.11 & 13.59 \\
$\mathrm{Ca}$ & 1.53 & 2.35 \\
$\mathrm{Mo}$ & 0.00 & 0.77 \\
$\mathrm{Fe}$ & 1.72 & 2.16 \\
Totals & 100.00 & 100.00 \\
\hline
\end{tabular}

not detected by the instrument. Consequently, the fibers are concentrated in the coarse fraction (diameter between $1 \mathrm{~mm}-0.063 \mathrm{~mm}$ ). This is confirmed by XRPD and SEM-EDS analysis.

ED-XRF analysis show high presence of $\mathrm{Fe}$ and $\mathrm{S}$ and other metals as $\mathrm{Ni}, \mathrm{Cr}, \mathrm{Cu}$ and $\mathrm{Zn}$ in the bituminous fraction. These elements could be related to vehicular traffic pollution that could be adsorbed by the fracture in the asphalt. The bituminous composition could be related to a typical bitumen of Mexican Blend or California type (Riala, 1998). Instead of, the majority of the clasts are characterized by calcium carbonate and also dolomite. No asbestos had been observed.

XRPD results confirm that clasts in all the analyzed samples are constituted by the prevalence of calcite and dolomite, with also some quartz. Small amount of tremolite species are present in the three analyzed samples, while small peaks of chrysotile appears in sample 2 .

SEM-EDS imaging and data confirm the presence of asbestos in sample 2, especially in the fraction with diameter between $1 \mathrm{~mm}$ and
$0.063 \mathrm{~mm}$.

As suggested from Militello et al. (2019), the observations under OM allowed us to investigate the textures and the spatial relations between the mineralogical phases and the identification of asbestos minerals could be easy under OM, but even at higher magnifications a fiber habit has the same geometric parameters of prismatic/acicular crystals. Under SEM it is better characterize the aspect ratios and the textural relations between the various phases-often the habit is detectable, but discrimination among the serpentine polymorphs is not simple and not always possible. For these reasons, could be plausible implement the analysis with TEM observations, that allow high-resolution discrimination for EMP and an effective distinction between regulated and non-regulated asbestos minerals. Moreover, for better characterize samples and mineralogical phases with more attention to fiber phases, synchrotron radiation X-ray micro-tomography could be a technique that offers the possibility to observe and image the $3 \mathrm{D}$ morphology and the spatial relationship between the mineral phases that constituted the investigated samples. Furthermore, it is a semidestructive technique which allows the analysis of samples under high magnification without grinding/milling and or the loss of their morphology. Nevertheless, it provides qualitative and volumetric but not quantitative information of the mineralogical phases; therefore, it proved a complementary technique to other conventional ones.

In general, asbestos fibers in asbestos-containing roofing materials are encapsulated in bituminous matrices or resins, thereby binding the fibers and preventing their release (NRCA, 1994). During their work, many roofers may have been exposed to asbestos during the repair or tear-off of old roofing materials, including roofing cements and coatings. Very few studies have reported airborne concentrations of asbestos associated with the application, repair or removal of roof coatings or cements. 

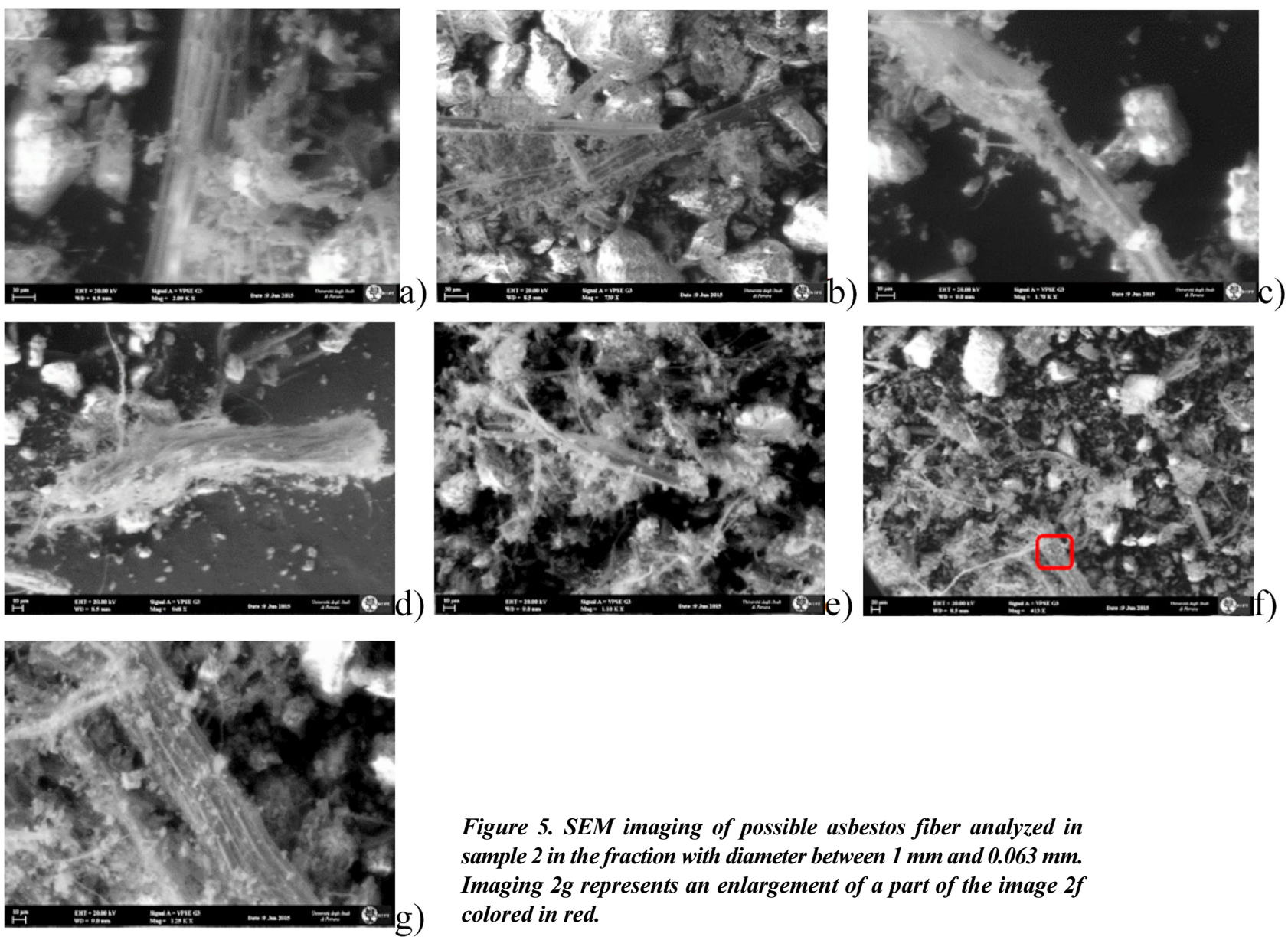

Figure 5. SEM imaging of possible asbestos fiber analyzed in sample 2 in the fraction with diameter between $1 \mathrm{~mm}$ and $0.063 \mathrm{~mm}$. Imaging $2 g$ represents an enlargement of a part of the image $2 f$ colored in red.

Mowat (2007) indicates a low probability that asbestos will become airborne during manipulation of coating- and cement-type roofing products such as those tested. The results indicate an exceedingly small asbestos exposure associated with the repair of these products, even during the unlikely 30 -min application, hand scraping and sanding of these products from roof substrates.

\section{References}

Androjić, I., Alduk, Z.D., Dimter, S., and Rubkavina, T., 2020, Analysis of impact of aggregate moisture content on energy demand during the production of hot mix asphalt (HMA). Journal of Cleaner Production, v. 244, pp. 118868. doi.org/10.1016/j.jclepro.2019.118868

Assogba, O.C., Tan, Y., Zhou, X., Zhang, C., and Anato, J.N., 2020, Numerical investigation of the mechanical response of semi-rigid base asphalt pavement under traffic load and nonlinear temperature gradient effect. Construction and Building Materials, v. 235, pp. 117406. doi.org/10.1016/ j.conbuildmat.2019.117406

Belluso, E., Cavallo, A., and Halterman, D., 2017, Crystal habit of mineral fibres. In Mineral Fibres: Crystal Chemistry, Chemical-Physical Properties, Biological Interaction and Toxicity; Gualtieri A.F. Ed.; European Mineralogical Union: London, UK, v. 18, pp. 65-109. doi.org/10.1180/ EMU-notes. 18.3

Bonica, C., Toraldo, E., Andena, L., Marano, C., and Mariani E., 2016, The effects of fibers on the performance of bituminous mastics for road pavements. Composites Part B: Engineering, v. 95, pp. 76-81. doi.org/ 10.1016/j.compositesb.2016.03.069

Bourgault, M.H., Gagné, M., and Valcke, M., 2014, Lung cancer and mesothe- lioma risk assessment for a population environmentally exposed to asbestos. International Journal of Hygiene and Environmental Health, v. 217, pp. 340-346. doi.org/10.1016/j.ijheh.2013.07.008

Chen, H., Xu, Q., Chen, S, and Zhang, Z., 2009, Evaluation and design of fiber-reinforced asphalt mixtures. Materials and Design, v. 30, pp. 2595-2603. doi.org/10.1016/j.matdes.2008.09.030

Council Directive 67/548/EEC of 27 June 1967 on the approximation of laws, regulations and administrative provisions relating to the classification, packaging and labelling of dangerous substances.

Cox Jr, L.A., 2019, Dose-response modeling of NLRP3 inflammasomemediated diseases: asbestos, lung cancer, and malignant mesothelioma as examples. Critical Reviews in Toxicology, v. 49, pp. 614-635. doi.org/ 10.1080/10408444.2019.1692779

Du, W., Wang, G., Wang, Y., and Liu, X., 2019, Thermal degradation of bituminous coal with both model-free and model-fitting methods. Applied Thermal Engineering, v. 152, pp. 169-174. doi.org/10.1016/j.applthermaleng.2019.02.092

EC Regulation 1272/2008 of the European Parliament and of the Council of 16 December 2008 on classification, labelling and packaging of substances and mixtures, amending and repealing Directives 67/548/EEC and 1999/45/EC, and amending Regulation (EC) No 1907/2006.

Falini, G., Foresti, E., Lescia, G., and Roveri, N., 2002, Structural and morphological characterization of synthetic chrysotile single crystals. Chemical Communications, v. 14. doi.org/10.1039/B203430A

Fitzgerald, R.C., and Rhodes, J.M., 2019, Ingested asbestos in filtered beer, in addition to occupational exposure, as a causative factor in oesophageal adenocarcinoma. British Journal of Cancer, v. 120, pp. 1099-1104. doi.org/ 10.1038/s41416-019-0467-9

Greene, B., 1992, Asphalt Construction Handbook. 6th ed. A Division of Caterpillar Paving Products Inc. 
Gronow, J., 1987, The dissolution of asbestos fibres in water. Clay Minerals, v. 22, pp. 21-35. doi.org/10.1180/claymin.1987.022.1.03

Heidrich, J., Wolff, C., Centmayer, A., Wiethege, T., Dueli, M., Taeger, D., and Harth, V., 2019, Lung cancer screening by low-dose CT among asbestosexposed workers: first results of a pilot program. European Journal of Public Health, v. 29, pp. 503-504. doi.org/10.1093/eurpub/ckz186.325

Kimizuka, G., Wang, N.S., and Hayashi, Y., 1987, Physical and microchemical alterations of chrysotile and amosite asbestos in the hamster lung. Journal of Toxicology and Environmental Health, v. 21, pp. 251264. doi.org/10.1080/15287398709531017

Kromhout, H., Feletto, E., Moissonnier, M., Schonfeld, S., Olsson, A., Kovalevskij, E.V., Bukhtiyarov, I.V., Kashanskiy, S.V., and Schüz, J., 2019, O1C.5 Assessment and assignment of exposure to asbestos for an industrial cohort of chrysotile miners and processors. Occupational and Environmental Medicine, v. 76, pp. A8. doi.org/10.1136/OEM2019-EPI.21

Landi, D., Marconi, M., Bocci, E., and Germani, M., 2020, Comparative life cycle assessment of standard, cellulose-reinforced and end of life tires fiber-reinforced hot mix asphalt mixtures. Journal of Cleaner Production, v. 248, pp. 119-295. doi.org/10.1016/j.jclepro.2019.119295

Marrocchino, E., Rapti-Caputo, D., and Vaccaro C., 2010, Chemical-mineralogical characterisation as useful tool in the assessment of the decay of the Mesola Castle (Ferrara, Italy). Construction and Building Materials, v. 24, pp. 2672-2683. doi.org/10.1016/j.conbuildmat.2010.04.063

Militello, G.M., Bloise, A., Gaggero, L., Lanzafame, G., and Punturo, R., 2019, Multi-Analytical Approach for Asbestos Minerals and Their Non-Asbestiform Analogues: Inferences from Host Rock Textural Constraints. Fibers, v. 7, pp. 42. doi.org/10.3390/fib7050042

Mokhtari, M., Jafari, N., Mohammadi, A., Hajizadeh Y., Ghanbari R., Nemati S., and Abdolahnejad A., 2019, Temporal and spatial trends of airborne asbestos fiber concentrations in the urban areas of Yazd, Iran. International Journal of Environmental Science and Technology, v. 16, pp. 2657-2666. doi.org/10.1007/s13762-018-1858-9

Moreno-Navarro, F., Sol-Sánchez, M., and Rubio-Gámez, M.C., 2017, Structural analysis of polymer modified bituminous materials in the rehabilitation of light-medium traffic volume roads. Construction and Building Materials, v. 156, pp. 621-631. doi.org/10.1016/j.conbuildmat. 2017.09.006

Mowat, F., Weidling, R., and Sheehan, P., 2007, Simulation Tests to Assess Occupational Exposure to Airborne Asbestos from Asphalt-Based Roofing Products. Annals of occupational hygiene, v. 51, pp. 451-462. doi.org/ 10.1093/annhyg/mem020

Nishimura, Y., Kumagai-Takei, N., Lee, S., Yoshitome, K., and Otsuki, T., 2020, Suppressed Immune System Caused by Exposure to Asbestos and Malignant Mesothelioma. Asbestos-related Diseases [Online First], IntechOpen. doi.org/10.5772/intechopen.90763

Noonan, C.W., and Pfau J.C., 2011, Asbestos Exposure and Autoimmune Disease. Encyclopedia of Environmental Health, pp. 193-203.

NRCA, 1994, Objective data demonstration for certain roofing materials and operations under OSHA's 1994 asbestos standard, December 14. Rosemont, IL: National Roofers Contractors Association.

Paglietti, F., Malinconico, S., Conestabile della Staffa, B., Bellagamba, S., and De Simone, P., 2016, Classification and management of asbestoscontaining waste: European legislation and the Italian experience. Waste Management, v. 50, pp. 130-150. doi.org/10.1016/j.wasman. 2016.02.014

Pfau, J.C., and Noonan, C.W., 2019, Asbestos Exposure and Autoimmune
Disease. Encyclopedia of Environmental Health (Second Edition), pp. 181-190.

Punturo, R., Ricchiuti, C., Rizzo, M., Marrocchino, E., 2019, Mineralogical and Microstructural Features of Namibia Marbles: insights about Tremolite related to natural asbestos occurrences. Fibers, v. 7, pp. 31. doi.org/10.3390/ fib7040031

Qian, G., Yao, D., Gong, X., Yu, H., and Li, N., 2019, Performance evaluation and field application of hard asphalt concrete under heavy traffic conditions. Construction and Building Materials, v. 228, pp. 116729. doi.org/10.1016/j.conbuildmat.2019.116729

Riala, R., Heikkila, P., and Kanerva, L.A., 1998, A questionnaire study of road pavers' and roofers' work-related skin symptoms and bitumen exposure. International Journal of Dermatology, v. 37, pp. 27-30. doi.org/ 10.1046/j.1365-4362.1998.00226.x

Romera, R, Santamaría, A, Peña, J.J., Muñoz, M.E., Barral, M., García, E., and Jañez, V., 2016, Rheological aspects of the rejuvenation of aged bitumen. Rheologica acta, v. 45, pp. 474-478. doi.org/10.1007/s00397-0050078-7

Sąkol, G., and Muszyńska-Graca, M., 2019, Air Pollution during Asbestos Removal. Polish Journal of Environmental Studies, v. 28, pp. 1007-1011. doi.org/10.15244/pjoes/81616

Slebi-Acevedo, C.J., Lastra-González, P., Pascual-Muñoz, P., and CastroFresno, D., 2019, Mechanical performance of fibers in hot mix asphalt: A review. Construction and Building Materials, v. 200, pp. 756-769. doi.org/10.1016/j.conbuildmat.2018.12.171

Taghizadeh, F., Jafari, A.J., Gholami, M., Kermani, M., Arfaeinia, H., Mohammadi, S., Dowlati, M., and Shahsavani, A., 2019, Monitoring of airborne asbestos fibers in an urban ambient air of Shahryar City, Iran: levels, spatial distribution, seasonal variations, and health risk assessment. Environmental Science and Pollution Research, v. 26, pp. 6450-6459. doi.org/ 10.1007/s11356-018-4029-0

Telloli, C., Chicca, M., Pepi, S., and Vaccaro, C., 2018, Saharan dust particles in snow samples of Alps and Apennines during an exceptional event of transboundary air pollution. Environmental Monitoring and Assessment, v. 190, pp. 37. doi.org/10.1007/s10661-017-6412-6

Topini, D., Toraldo, E., Andena, L., and Mariani, E., 2018, Use of recycled fillers in bituminous mixtures for road pavements. Construction and Building Materials, v. 159, pp. 189-197. doi.org/10.1016/j.conbuildmat.2017.10.105

U.S Department of Health and Human Services. $9^{\text {th }}$ Report on Carcinogens. Revised January 2001, National Toxicology Program. Pursuant to Section 301(b) (4) of the Public Health Service Act as Amended by Section 262, PL 95-622.

Xiong, R., Fang, J., Xu, A., Guan, B., and Liu, Z., 2015, Laboratory investigation on the brucite fiber reinforced asphalt binder and asphalt concrete. Construction and Building Materials, v. 83, pp. 44-52. doi.org/10.1016/ j.conbuildmat.2015.02.089

Xu, Q., Chen, H., and Prozzi, J.A., 2010, Performance of fiber reinforced asphalt concrete under environmental temperature and water effects. Construction and Building Materials, v. 24, pp. 2003-2010. doi.org/10.1016/ j.conbuildmat.2010.03.012

Zheng, B., Zang, L., Li, W., Li, H., Wang, H., Zhang, M., and Song, X., 2019, Quantitative analysis of asbestos in drinking water and its migration in mice using fourier-transform infrared spectroscopy and inductively coupled plasma optical emission spectrometry. Analytica Chimica Acta, v. 1058, pp. 29-38. doi.org/10.1016/j.aca.2018.12.022 


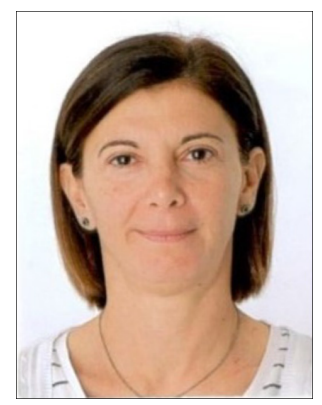

Elena Marrocchino Fabio Faccia. Graduated at the University of Ferrara in Geological Sciences in 2009. From 2013 to 2019 has been employed in ELLETIPI s.r.l. - DIMMS Group as Project Manager responsible for material tests laboratory and management of road construction site activities and laboratories. He was the coordinator of multidisciplinary investigations and laboratory tests on road, airport and structural construction sites. From 2019 to present he is working at SOCOTEC ITALIA s.r.l., as responsible for material tests laboratory and as technical manager of the Ferrara branch. He is the technical coordinator of construction and laboratory activities in the Ferrara Socotec Department.

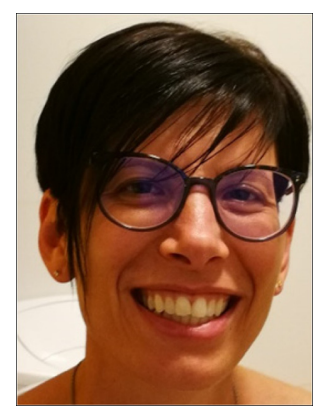

Chiara Telloli PhD in Earth Sciences. Since 2009 she has participated in different monitoring samplings for the estimation of emission factors in agricultural and anthropogenic activities. Since 2012, research grant at ENEA for particle measurement activities in urban areas. Since 2017, research grant at ENEA for the development of methods for the determination of carbon isotopes contained in ion exchange resins used in the nuclear industry and their chemical speciation in storage conditions in an alkaline humid environment. Since 2018, research grant at ENEA for the characterization of $14 \mathrm{C}$ and $36 \mathrm{Cl}$ in gaseous form from nuclear graphite.

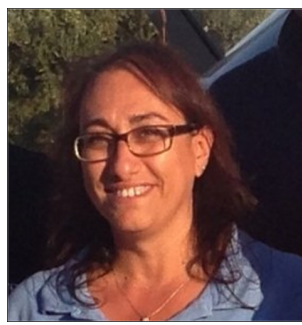

Antonietta Rizzo Head of ENEA Traceability Laboratory, Bologna (Italy). PhD in Chemical Sciences. Expert in chemical and physical techniques integration for interdisciplinary applications, she has worked in the fields of analytical techniques for radionuclides and nanotechnologies. She gained experience in technological innovation. From 2000 to 2006 researcher at ENEA in the noble gas spectrometric sector. From 2006 to 2009 researcher at ISMN-CNR in the nanotechnology sector. Since 2009 researcher at ENEA for radionuclides analytical techniques in the field of safety, traceability and management of radioactive waste and activities related to CTBT control and verification.

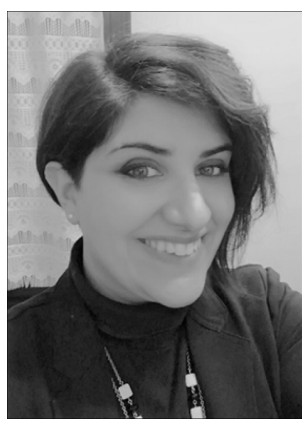

Lisa Volpe Graduated at University of Ferrara in "Technologies for Cultural Heritage" (BA, 2006) and in "Conservation and diagnostic of Modern, Contemporary Artworks" (MA, 2009). Ph.D. in Earth Sciences (University Ferrara, March 2013). In 2011, she became research fellow in conservation science concerned materials characterization through Microscopy (SEM/EDS, OM, POM) and EDXRF analysis (University Ferrara, TekneHub Lab - Dept. Physics and Earth Science, 2011-2017) and microbiological-chemical-physical monitoring of Environment and Cultural Heritage (University Ferrara, CIAS Lab - Dept. Architecture, 2017-2018). Special needs teacher at high school (school year 20182019). Since September 2019, researcher at ENEA DUEE-SPS-ESU (C.R. Casaccia, Rome)

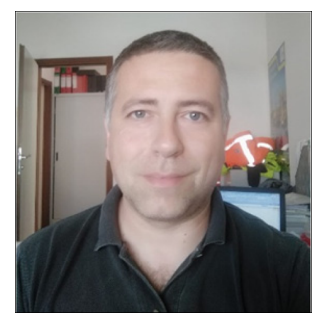

Fabio Faccia Graduated at University of Ferrara in Geological Sciences, 2009. From 2013 to 2019 employed in ELLETIPI s.r.1. - DIMMS Group as Project Manager responsible for material tests laboratory and management of road construction site activities and laboratories. He was the coordinator of multidisciplinary investigations and laboratory tests on road, airport and structural construction sites. From 2019- to present SOCOTEC ITALIA s.r.1., as responsible of the material tests laboratory and as technical manager of the Ferrara branch. He is the technical coordinator of construction and laboratory activities in the Socotec Department of Ferrara. 